\title{
Intra-abdominal infections: the role of different classifications on the selection of the best antibiotic treatment
}

\author{
João Silva-Nunes ${ }^{1 *}$ (i) and Teresa Cardoso ${ }^{1,2}$ (B)
}

\begin{abstract}
Background: Intra-abdominal infections (IAls) represent a most frequent gastrointestinal emergency and serious cause of morbimortality. A full classification, including all facets of IAls, does not exist. Two classifications are used to subdivide IAls: uncomplicated or complicated, considering infection extent; and community-acquired, healthcareassociated or hospital-acquired, regarding the place of acquisition. Adequacy of initial empirical antibiotic therapy prescribed is an essential need. Inadequate antibiotic therapy is associated with treatment failure and increased mortality. This study was designed to determine accuracy of different classifications of IAls to identify infections by pathogens sensitive to current treatment guidelines helping the selection of the best antibiotic therapy.

Methods: A retrospective cohort study including all adult patients discharged from hospital with a diagnosis of IAI between 1st of January and 31st of October, 2016. All variables potentially associated with pre-defined outcomes: infection by a pathogen sensitive to non-pseudomonal cephalosporin or ciprofloxacin plus metronidazole (ATB 1, primary outcome), sensitive to piperacillin-tazobactam (ATB 2) and hospital mortality (secondary outcomes) were studied through logistic regression. Accuracy of the models was assessed by area under receiver operating characteristics (AUROC) curve and calibration was tested using the Hosmer-Lemeshow goodness-of-fit test.
\end{abstract}

Results: Of 1804 patients screened 154 met inclusion criteria. Sensitivity to ATB 1 was independently associated with male gender (adjusted $O R=2.612$ ) and previous invasive procedures in the last year (adjusted $O R=0.424$ ) (AUROC curve $=0,65$ ). Sensitivity to ATB 2 was independently associated with liver disease (adjusted OR $=3.580$ ) and postoperative infections (adjusted OR $=2.944$ ) (AUROC curve $=0.604$ ). Hospital mortality was independently associated with age $\geq 70$ (adjusted $O R=4.677$ ), solid tumour (adjusted $O R=3.127$ ) and sensitivity to non-pseudomonal cephalosporin or ciprofloxacin plus metronidazole (adjusted $\mathrm{OR}=0.368$ ).

The accuracy of pre-existing classifications to identify infection by a pathogen sensitive to ATB 1 was 0.59 considering place of acquisition, 0.61 infection extent and 0.57 local of infection, for ATB 2 it was $0.66,0.50$ and 0.57 , respectively.

Conclusion: None of existing classifications had a good discriminating power to identify IAls caused by pathogens sensitive to current antibiotic treatment recommendations. A new classification, including patients' individual characteristics like those included in the current model, might have a higher potential to distinguish IAls by resistant pathogens allowing a better choice of empiric antibiotic therapy.

Keywords: Intra-abdominal infections, Classification, Antibiotic therapy, Hospital mortality

\footnotetext{
*Correspondence: joaonunes@me.com

${ }^{1}$ Instituto de Ciências Biomédicas Abel Salazar, Universidade do Porto

(ICBAS-UP), Rua de Jorge Viterbo Ferreira n. ${ }^{\circ} 228$, Porto 4050-313, Portugal

Full list of author information is available at the end of the article
}

(c) The Author(s). 2019 Open Access This article is distributed under the terms of the Creative Commons Attribution 4.0 International License (http://creativecommons.org/licenses/by/4.0/), which permits unrestricted use, distribution, and reproduction in any medium, provided you give appropriate credit to the original author(s) and the source, provide a link to the Creative Commons license, and indicate if changes were made. The Creative Commons Public Domain Dedication waiver (http://creativecommons.org/publicdomain/zero/1.0/) applies to the data made available in this article, unless otherwise stated. 


\section{Background}

Intra-abdominal infections (IAIs) represent one of the most frequent gastrointestinal emergencies and a serious cause of morbidity and mortality [1-6]. A full classification that includes all facets of IAIs does not exist. An optimal classification designed for clinicians' guidance in treatment should include: the origin of the source of infection, the anatomical extension, the supposed pathogens involved and risk factors for major resistance patterns, and the clinical condition of the patient $[2,6,7]$.

IAIs are most frequently subdivided as uncomplicated or complicated, considering the extent of infection [1, 2, 6-11]. An uncomplicated intra-abdominal infection (UIAI) is an infection that involves a single organ and does not extend to the peritoneum [1, 2, 4-13]. A complicated intra-abdominal infection (cIAI) extends beyond a single organ into the peritoneal space $[1,2,4-13]$.

Based on place of acquisition, infections are divided in: community-acquired intra-abdominal infection (CA-IAI) as an infection present at hospital admission or within $48 \mathrm{~h}$ in patients that did not meet the criteria for healthcare-associated infection and it is usually caused by the patient's own flora [3, 6, 9, 12-15], hospitalacquired intra-abdominal infections (HA-IAIs), defined as infections that were not present at the time of hospital admission but emerge as noticeable after at least $48 \mathrm{~h}$ in patients hospitalized for other purpose than IAIs [12, 15-17], and healthcare-associated infections (HCAIAIs) [18, 19], defined as infections present at hospital admission or within $48 \mathrm{~h}$ of admission in patients with previous contact with healthcare, namely invasive procedures, or that resides in a long-term care facility $[12,18]$.

The adequacy of initial empirical antibiotic therapy prescribed for IAIs is an essential need [1, 6, 9, 11, 12, 15], due to the minimum $48 \mathrm{~h}$ ' time required to have microbiological data available $[1,6,9,11]$. Suitable empiric antibiotic therapy has a huge impact on the outcome of patients diagnosed with IAIs [12, 15, 20-22]. In CA-IAI, antibiotics with a restricted spectrum of activity are suggested [6, 9, 12, 23], such as cephalosporins without Pseudomonas aeruginosa coverage plus metronidazole, ciprofloxacin plus metronidazole, and piperacillin/tazobactam $[6,9,12,24]$. In HA-IAIs, antibiotic regimens with vaster spectra of coverage are suggested $[6,9,11]$.

There is evidence that inadequate and/or delayed antibiotic therapy is associated with treatment failure and increased mortality [1, 12, 13, 20-22, 25-30]. The sensitive equilibrium between the enhancement of empirical antibiotic therapy, which was proved to promote better clinical results, and the decline of needless antimicrobial overuse, which has been linked to the increasing development of multi-drug resistant (MDR) pathogens, is invariably needed when treating infections [6, 12, 31].
This study was designed to assess the impact of the different classifications of IAIs in the selection of the best antibiotic therapy, considering the need of adequate empirical antibiotic therapy and public health need to preserve antibiotics.

\section{Methodology \\ Study design and selection}

A retrospective cohort study developed at Hospital de Santo António, Centro Hospitalar Universitário do Porto, a tertiary care university hospital, including all adult patients ( $\geq 18$ years old) discharged from the hospital with the diagnosis of IAI between 1st of January and 31st of October of 2016.

The main inclusion criteria were meeting the CDC definition of intra-abdominal infection (CDC. CDC/NHSN Surveillance Definitions for Specific Types of Infections. 2018; Available from: https://www.cdc.gov/nhsn/pdfs/ pscmanual/17pscnosinfdef_current.pdf). First selection of the patients was achieved using the International Statistical Classification of Diseases and Related Health Problems 9th revision (ICD-9) including those with a discharge code compatible with intra-abdominal infection [ICD-9 codes considered in Additional file 1]. For selected patients, clinical file was reviewed to inclusion criteria confirmed and data of interest retrieved [see Additional file 2].

Exclusion criteria were: patients with anal/rectal pathology, infections caused by non-bacterial pathogens (that is virus, fungus and protozoa), non-complicated appendicitis, tuberculosis and patients with negative or no culture results.

The following variables were collected: age, gender, functional status, previous comorbidities, hospital admission date, discharge date, place of acquisition of the infection (community-acquired, healthcare-associated or hospital-acquired), extent of infection (uncomplicated or complicated), localization of infection (appendix, biliary tract, colon, small intestine, stomach/duodenum or other), post-operative infection (perforation, suture dehiscence, tertiary peritonitis, undetermined or non-applicable), microorganism(s) isolated, location of the isolated pathogen, realization of blood cultures, blood cultures' result, resistance of isolated pathogens, empirical therapy administered to the patient in the first $24 \mathrm{~h}$ after diagnosis (antibiotic, daily dose, route of administration), change of the initial antibiotic therapy, reason of the changing, adequacy of the empirical antibiotic therapy, risk factors for healthcareassociated infections, previous colonization/infection by DR pathogen, previous antibiotic therapy (last 3 months), previous hospital admission (last year), previous invasive procedures (last year) and residence in a long-term care facility or nursing home and outcome at hospital discharge (dead or alive). 
Functional status was assessed by the Karnofsky Performance Status Scale (KPS) [32] and previous comorbidities by the Charlson Comorbidity Index (CCI) [33]. The initial empirical antibiotic therapy was considered appropriate if all of the bacteria isolated from cultures were sensitive to at least one of the drugs administered.

The primary outcome of interest was infection by a pathogen sensitive to the following antibiotic scheme: non-pseudomonal cephalosporin or ciprofloxacin plus metronidazole. Secondary outcomes were sensitivity to piperacillin/tazobactam and hospital mortality.

\section{Statistical analysis}

Data were described by means and standard deviations (SD) for continuous variables or with medians and interquartile ranges (IQR) if they showed a skewed distribution. Categorical variables were described with absolute frequencies and percentages. T-tests or Mann-Whitney$\mathrm{U}$ tests were used to compare continuous variables. For categorical variables, these comparisons were performed using Pearson $\chi^{2}$ and Fisher's exact tests.

All variables potentially associated with pre-defined outcomes were studied through logistic regression. Those with a clear association in the univariate analysis $(p<0.1)$ were included in the multivariable analysis. The results of the multivariable models are expressed as odds ratio (OR) with $95 \%$ confidence interval $\left(\mathrm{CI}_{95 \%}\right)$ and $p$ values. The accuracy of the models was assessed by the area under receiver operating characteristics (AUROC) curve and calibration was tested using the HosmerLemeshow goodness-of-fit test. The significance level was defined as $p<0.05$.

Data were analysed using the Statistical Package for the Social Sciences (SPSS) version 25 for Windows (SPSS Inc., Chicago, IL, USA).

\section{Results}

There were 1804 patients discharged from the hospital during the study period that met the ICD-9 established criteria. Of these, 154 met the inclusion criteria (Fig. 1).

Patients included in the study had a mean \pm SD age of $73 \pm 14$ years and $48 \%$ were male; $112(73 \%)$ need some help for daily activities defined by a KPS scale $<70$ and $31(20 \%)$ patients had no comorbidities according to the CCI definitions (Table 1). Median (IQR) hospital length of stay was 17 [1029 ] days and hospital mortality rate was $22 \%(n=34)$.

The following risk factors were associated with an IAI by pathogens sensitive to ATB 1: male gender, previous antibiotic therapy and previous invasive procedures (Table 1). The final model retained male gender with an adjusted OR $\left(\mathrm{CI}_{95 \%}\right)=2.612(1.328$ 5.148 ) and previous invasive procedures in the last year with an adjusted OR $\left(\mathrm{Cl}_{95 \%}\right)=0.424 \quad(0.216$ 0.833). The AUROC curve $\left(\mathrm{CI}_{95 \%}\right)$ was 0.65 (0.570.74) (Table 2).

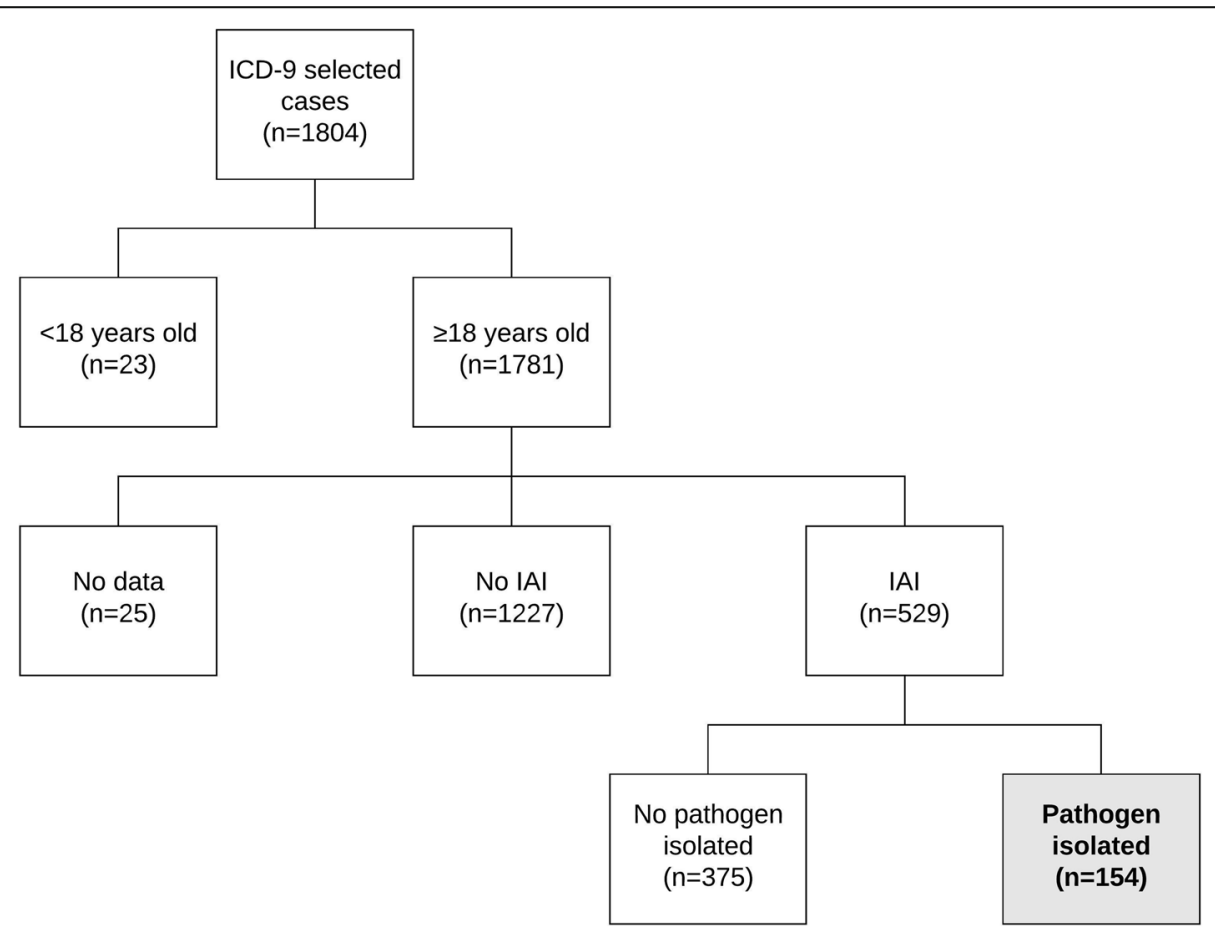

Fig. 1 Flow diagram of the population selection process. (ICD-9, International Statistical Classification of Diseases and Related Health Problems 9th revision; IAI, intra-abdominal infection) 
Table 1 Population's general characteristics and risk factors for IAI by pathogens sensitive to ATB 1 or to ATB 2

\begin{tabular}{|c|c|c|c|c|c|}
\hline & Total & $\begin{array}{l}\text { IAl by pathogens } \\
\text { susceptible to ATB } 1\end{array}$ & $p$ value & $\begin{array}{l}\text { IAl by pathogens } \\
\text { susceptible to ATB } 2\end{array}$ & $p$ value \\
\hline Age $\geq 70, n(\%)$ & $101(66)$ & $52(65)$ & 0.874 & $72(64)$ & 0.253 \\
\hline Male gender, n (\%) & $74(48)$ & $46(58)$ & 0.015 & $49(47)$ & 0.614 \\
\hline Karnofsky Performance Status Scale < 70, n (\%) & $112(73)$ & $62(78)$ & 0.167 & $73(70)$ & 0.191 \\
\hline Diabetes, n (\%) & $45(29)$ & $19(24)$ & 0.121 & $28(27)$ & 0.308 \\
\hline Liver disease, n (\%) & $14(9)$ & $6(8)$ & 0.475 & $6(6)$ & 0.033 \\
\hline Solid tumour, n (\%) & $45(29)$ & $23(29)$ & 0.894 & $31(30)$ & 0.904 \\
\hline AIDS, n (\%) & $1(1)$ & $1(1)$ & $1.000^{\mathrm{a}}$ & $1(1)$ & $1.000^{\mathrm{a}}$ \\
\hline Chronic kidney disease, n (\%) & $26(17)$ & $9(11)$ & 0.052 & $18(17)$ & 0.900 \\
\hline Congestive heart failure, $\mathrm{n}(\%)$ & $11(7)$ & $7(9)$ & $0.537^{\mathrm{a}}$ & $8(8)$ & $1.000^{\mathrm{a}}$ \\
\hline Myocardial infarction, n (\%) & $10(7)$ & $7(9)$ & $0.331^{\mathrm{a}}$ & $9(9)$ & $0.171^{\mathrm{a}}$ \\
\hline Chronic obstructive pulmonary disease, n (\%) & $10(7)$ & $6(8)$ & $0.748^{\mathrm{a}}$ & $8(8)$ & $0.504^{\mathrm{a}}$ \\
\hline Peripheral vascular disease, n (\%) & $22(14)$ & $11(14)$ & 0.843 & $14(13)$ & 0.621 \\
\hline Cerebrovascular accident/transient ischemic attack, n (\%) & $14(9)$ & $8(10)$ & 0.683 & $11(11)$ & $0.550^{\mathrm{a}}$ \\
\hline Dementia, n (\%) & $11(7)$ & $3(4)$ & $0.120^{\mathrm{a}}$ & $7(7)$ & $1.000^{\mathrm{a}}$ \\
\hline Hemiplegia, n (\%) & $1(1)$ & $1(1)$ & $1.000^{\mathrm{a}}$ & $1(1)$ & $1.000^{\mathrm{a}}$ \\
\hline Connective tissue disease, $\mathrm{n}(\%)$ & $2(1)$ & $1(1)$ & $1.000^{\mathrm{a}}$ & $1(1)$ & $1.000^{\mathrm{a}}$ \\
\hline Leukemia, n (\%) & $3(2)$ & $1(1)$ & $0.608^{\mathrm{a}}$ & $2(2)$ & $1.000^{\mathrm{a}}$ \\
\hline Malignant lymphoma, n (\%) & $1(1)$ & $1(1)$ & $1.000^{\mathrm{a}}$ & $1(1)$ & $1.000^{\mathrm{a}}$ \\
\hline Peptic ulcer disease, n (\%) & $4(3)$ & $3(4)$ & $0.621^{a}$ & $3(3)$ & $1.000^{\mathrm{a}}$ \\
\hline Total score - Charlson Comorbidity Index, mean \pm SD & $5 \pm 3$ & $5 \pm 3$ & 0.744 & $5 \pm 3$ & 0.352 \\
\hline Residence in a long-term care facility or nursing home, n (\%) & $7(5)$ & $2(3)$ & $0.259^{\mathrm{a}}$ & $4(4)$ & $0.681^{a}$ \\
\hline Previous colonization/infection by DR pathogen, n (\%) & $29(19)$ & $16(20)$ & 0.700 & $20(19)$ & 0.920 \\
\hline Previous antibiotic therapy, n (\%) & $39(25)$ & $14(18)$ & 0.020 & $22(21)$ & 0.068 \\
\hline Previous hospitalization, n (\%) & $82(53)$ & $37(46)$ & 0.070 & $51(49)$ & 0.089 \\
\hline Previous invasive procedures, $\mathrm{n}(\%)$ & $78(51)$ & $34(43)$ & 0.028 & $48(46)$ & 0.082 \\
\hline Post-operative Infection, n (\%) & $19(12)$ & $9(11)$ & 0.670 & $9(9)$ & 0.037 \\
\hline
\end{tabular}

${ }^{\mathrm{a}}$ Fisher's exact test; AIDS, acquired immune deficiency syndrome; ATB 1, non-pseudomonal cephalosporin or ciprofloxacin plus metronidazole; ATB 2, piperacillin/ tazobactam; $D R$ drug-resistant, $O R$ odds ratio, $S D$ standard deviation

Considering ATB 2 as the dependent variable, the final model retained liver disease with an adjusted $\mathrm{OR}\left(\mathrm{Cl}_{95 \%}\right)=$ $3.580(1.126-10.879)$ and post-operative infections with an adjusted OR $\left(\mathrm{CI}_{95 \%}\right)=2.944(1.096-7.908)$ (Table 1). The AUROC curve $\left(\mathrm{Cl}_{95 \%}\right)$ was 0.604 (0.504-0.704) (Table 2).

\section{Intra-abdominal infections classification and microbiological results}

Comparison of the accuracy of different classifications of the IAI in determining infection by a pathogen sensitive to current treatment guidelines is shown in Table 2.

Table 2 Discriminative power of each classification for IAI by pathogen sensitive to antibiotic scheme for CA-IAI

\begin{tabular}{lll}
\hline Classification of intra-abdominal infection & AUROC curve (95\% CI) for ATB 1 & AUROC curve (95\% Cl) for ATB 2 \\
\hline Place of acquisition: CA-IAI, HCA-IAI, HA-IAI & $0.59(0.50-0.68)$ & $0.66(0.56-0.75)$ \\
Place of acquisition: CA-IAI and HA-IAI & $0.54(0.45-0.63)$ & $0.59(0.49-0.69)$ \\
Extent of infection: UIAI or CIAI & $0.61(0.52-0.70)$ & $0.50(0.40-0.60)$ \\
Local of infection & $0.57(0.48-0.66)$ & $0.57(0.48-0.67)$ \\
Current model & $0.65(0.57-0.74)$ & $0.60(0.50-0.70)$
\end{tabular}

AUROC area under receiver operating characteristics, Cl confidence interval, ATB I, non-pseudomonal cephalosporin or ciprofloxacin plus metronidazole, ATB 2 piperacillin/tazobactam, CA-IAI community-acquired intra-abdominal infection, $H C A-I A I$ healthcare-associated intra-abdominal infection, $H A-I A I$ hospital-acquired intra-abdominal infection, UIAI uncomplicated intra-abdominal infection, CIAl complicated intra-abdominal infection 
Postoperative infection was observed in 19 (12\%) patients, caused by suture dehiscence in $8(5 \%)$ patients, perforation in $3(2 \%)$ patients and undetermined or by other causes in $8(5 \%)$ patients.

Blood cultures were drawn in $122(79 \%)$ patients at hospital admission, of those 69 (57\%) were positive. Besides blood, pathogens were isolated from peritoneal fluid in 60 (39\%), bile in 13 (8\%), faeces in $11(7 \%)$, abscess in 9 (5\%), biliary drainage fluid in $1(1 \%)$ and pancreas drainage fluid in 1 (1\%).

The microbiological profile according to different classifications is shown in Table 3.

\section{Antibiotic therapy}

Although non-pseudomonal cephalosporin or ciprofloxacin plus metronidazole is the shorter spectrum recommended antibiotic therapy for CA-IAI, it was administered to only one patient, but if it was administered to all patients, it would have been adequate in $54 \%$ of them.

Among the antibiotic agents administered, piperacillin/tazobactam was the most frequently used, in 123 $(80 \%)$ patients, followed by metronidazole in 7 (5\%), imipenem plus cilastatin in $6(4 \%)$, ciprofloxacin in 5 (3\%) and amoxicillin/clavulanic acid in 4 (3\%). Nevertheless, the sensitivity to piperacillin/tazobactam was exhibited in $105(68 \%)$ patients.

The distribution of sensitive pathogens to the studied antibiotic regimens (non-pseudomonal cephalosporin or ciprofloxacin plus metronidazole, or piperacillin/tazobactam), according to the different classifications is shown in Table 3.

The empirical antibiotic therapy was changed in 83 (54\%) patients, of these adjustments to the susceptibility profile of the isolated pathogen was the most frequent reason in $40(48 \%)$ patients.

The initial antibiotic therapy was adequate in 98 (64\%) patients: $60(72 \%)$ with CA-IAIs, $26(56 \%)$ with HCAIAIs and $12(46 \%)$ with HA-IAIs $(p=0.034)$. In uIAI, 17 (68\%) patients had adequate initial antibiotic therapy and in cIAI $81(63 \%)$ patients $(p=0.620)$. There was no relation between the local of infection and the adequacy of the initial antibiotic therapy $(p=0.628)$.

In patients with post-operative infections, a higher frequency of inadequate antibiotic therapy was observed (63\% vs. $33 \%, p=0.010)$.

Table 3 Microbiological profile of IAI according to the different classifications

\begin{tabular}{|c|c|c|c|}
\hline Place of acquisition, $\mathrm{n}(\%)$ & CA-IAI, 83 (54) & HCA-IAl, 45 (29) & HA-IAI, 26 (17) \\
\hline Microbiological profile, n (\%) & $\begin{array}{l}\text { Monomicrobial, } 46 \text { (55) } \\
\text { E. coli, } 19 \text { (41) } \\
\text { Klebsiella spp., } 7 \text { (15) } \\
\text { E. faecium, } 4 \text { (19) } \\
\text { Other, } 16 \text { (25) } \\
\text { Polymicrobial, } 37 \text { (45) }\end{array}$ & $\begin{array}{l}\text { Monomicrobial, } 32 \text { (61) } \\
\text { E. coli, } 7 \text { (22) } \\
\text { Klebsiella spp., } 7 \text { (22) } \\
\text { Clostridium spp., } 6 \text { (19) } \\
\text { Other, } 12 \text { (37) } \\
\text { Polymicrobial, } 13 \text { (29) }\end{array}$ & $\begin{array}{l}\text { Monomicrobial, } 17 \text { (65) } \\
\text { E. coli, } 4 \text { (24) } \\
\text { Klebsiella spp., } 2 \text { (12) } \\
\text { E. faecium, } 2 \text { (12) } \\
\text { Clostridium spp., } 2 \text { (12) } \\
\text { Other, } 7 \text { (40) } \\
\text { Polymicrobial, } 9 \text { (35) }\end{array}$ \\
\hline IAI by pathogens sensitive to ATB I, $n(\%)$ & $50(60)$ & $20(44)$ & $10(40)$ \\
\hline IAI by pathogens sensitive to ATB $2, n(\%)$ & $66(80)$ & $27(60)$ & $12(46)$ \\
\hline Extent of infection, n (\%) & & ulAl, 25 (16) & ClAl, 129 (84) \\
\hline Microbiological profile, n (\%) & & $\begin{array}{l}\text { Monomicrobial, } 15 \text { (60) } \\
\text { Clostridium spp., } 9 \text { (60) } \\
\text { E. coli, } 2 \text { (13) } \\
\text { E. faecium, } 2 \text { (13) } \\
\text { Other, } 2 \text { (13) } \\
\text { Polymicrobial, } 10 \text { (40) }\end{array}$ & $\begin{array}{l}\text { Monomicrobial, } 80 \text { (62) } \\
\text { E. coli, } 28 \text { (35) } \\
\text { Klebsiella spp., } 16 \text { (20) } \\
\text { E. faecium, } 8 \text { (10) } \\
\text { Other, } 28 \text { (35) } \\
\text { Polymicrobial, } 49 \text { (38) }\end{array}$ \\
\hline IAI by pathogens sensitive to ATB I, $n(\%)$ & & $5(20)$ & $75(60)$ \\
\hline IAI by pathogens sensitive to ATB 2, n (\%) & & $17(68)$ & $88(68)$ \\
\hline Local of infection, n (\%) & Biliary Tract, 78 (51) & Colon, 43 (28) & Other, 33 (21) \\
\hline Microbiological profile, n (\%) & $\begin{array}{l}\text { Monomicrobial, } 54 \text { (69) } \\
\text { E. coli, } 23 \text { (43) } \\
\text { Klebsiella spp., } 13 \text { (24) } \\
\text { E. faecium, } 7 \text { (13) } \\
\text { Other, } 35 \text { (45) } \\
\text { Polymicrobial, } 24 \text { (31) }\end{array}$ & $\begin{array}{l}\text { Monomicrobial, } 21 \text { (49) } \\
\text { Clostridium spp., } 11 \text { (52) } \\
\text { E. coli, } 3 \text { (14) } \\
\text { E. faecium, } 2 \text { (10) } \\
\text { Other, } 5 \text { (24) } \\
\text { Polymicrobial, } 22 \text { (51) }\end{array}$ & $\begin{array}{l}\text { Monomicrobial, } 20 \text { (60) } \\
\text { Polymicrobial, } 13 \text { (40) }\end{array}$ \\
\hline IAI by pathogens sensitive to ATB I, $n(\%)$ & $42(54)$ & $20(47)$ & $18(55)$ \\
\hline IAI by pathogens sensitive to ATB $2, \mathrm{n}(\%)$ & $51(65)$ & $32(74)$ & $22(67)$ \\
\hline
\end{tabular}

ATB I, non-pseudomonal cephalosporin or ciprofloxacin plus metronidazole; ATB 2, piperacillin/tazobactam; CA-IAI, community-acquired intra-abdominal infection; HCA-IAI, healthcare-associated intra-abdominal infection; HA-IAI, hospital-acquired intra-abdominal infection; ulAI, uncomplicated intra-abdominal infection; cIAI, complicated intra-abdominal infection 


\section{Prognostic risk factors in intra-abdominal infections}

Factors significantly associated with hospital mortality were: KPS score $<70$, chronic kidney disease, the total score of CCI, localization of infection, polymicrobial flora and sensitivity to non-pseudomonal cephalosporin or ciprofloxacin plus metronidazole (Table 4).

In the multivariable analysis with the hospital mortality as the dependent variable, the final model retained

Table 4 Risk factors for hospital mortality

\begin{tabular}{|c|c|c|c|c|}
\hline & Total & Hospital mortality & $p$ value & Crude OR \\
\hline Age $\geq 70, n(\%)$ & $101(66)$ & $27(27)$ & 0.055 & 2.398 \\
\hline Male gender, n (\%) & $74(48)$ & $13(18)$ & 0.194 & 0.599 \\
\hline Karnofsky Performance Status Scale < 70, n (\%) & $112(73)$ & $20(18)$ & 0.042 & 0.435 \\
\hline Diabetes, n (\%) & $45(29)$ & $10(22)$ & 0.978 & 0.988 \\
\hline Liver disease, n (\%) & $14(9)$ & $4(29)$ & $0.512^{\mathrm{a}}$ & 1.467 \\
\hline Solid tumour, n (\%) & $45(29)$ & $14(31)$ & 0.082 & 2.010 \\
\hline AIDS, n (\%) & $1(1)$ & $0(0)$ & $1.000^{\mathrm{a}}$ & - \\
\hline Chronic kidney disease, n (\%) & $26(17)$ & $10(39)$ & 0.027 & 2.708 \\
\hline Congestive heart failure, n (\%) & $11(7)$ & $0(0)$ & $0.124^{\mathrm{a}}$ & - \\
\hline Myocardial infarction, n (\%) & $10(7)$ & $1(10)$ & $0.461^{\mathrm{a}}$ & 0.374 \\
\hline Chronic obstructive pulmonary disease, n (\%) & $10(7)$ & $3(30)$ & $0.693^{\mathrm{a}}$ & 1.562 \\
\hline Peripheral vascular disease, n (\%) & $22(14)$ & $4(18)$ & $0.785^{a}$ & 0.756 \\
\hline Cerebrovascular accident/transient ischemic attack, n (\%) & $14(9)$ & $0(0)$ & $0.041^{\mathrm{a}}$ & - \\
\hline Dementia, n (\%) & $11(7)$ & $5(46)$ & $0.066^{\mathrm{a}}$ & 3.276 \\
\hline Hemiplegia, n (\%) & $1(1)$ & $0(0)$ & $1.000^{\mathrm{a}}$ & - \\
\hline Connective tissue disease, n (\%) & $2(1)$ & $1(50)$ & $0.394^{\mathrm{a}}$ & 3.606 \\
\hline Leukemia, n (\%) & $3(2)$ & $2(67)$ & $0.123^{\mathrm{a}}$ & 7.437 \\
\hline Malignant lymphoma, n (\%) & $1(0,6)$ & $0(0)$ & $1.000^{\mathrm{a}}$ & - \\
\hline Peptic ulcer disease, n (\%) & $4(3)$ & $0(0)$ & $0.576^{\mathrm{a}}$ & - \\
\hline Total Score - Charlson Comorbidity Index, mean \pm SD & $5 \pm 3$ & $5 \pm 3$ & 0.045 & 0.866 per point \\
\hline Residence in a long-term care facility or nursing home, n (\%) & $7(5)$ & $2(29)$ & $0.469^{\mathrm{a}}$ & 1.484 \\
\hline Previous colonization/infection by DR pathogen, n (\%) & $29(19)$ & $4(14)$ & $0.322^{\mathrm{a}}$ & 0.507 \\
\hline Previous antibiotic therapy, n (\%) & $39(25)$ & $11(28)$ & 0.286 & 1.571 \\
\hline Previous hospitalization, n (\%) & $82(53)$ & $19(23)$ & 0.727 & 1.146 \\
\hline Previous invasive procedures, n (\%) & $78(51)$ & $18(23)$ & 0.644 & 1.200 \\
\hline Initial antibiotic therapy adequate, n (\%) & $98(64)$ & $21(21)$ & 0.797 & 0.902 \\
\hline Polymicrobial flora, n (\%) & $59(38)$ & $18(31)$ & 0.049 & 2.168 \\
\hline Sensitive to ATB I, n (\%) & $80(52)$ & $12(15)$ & 0.030 & 0.417 \\
\hline Sensitive to ATB 2, n (\%) & $105(68)$ & $19(18)$ & 0.084 & 0.501 \\
\hline Positive blood cultures, n (\%) & $69(57)$ & $16(15)$ & 0.065 & 0.429 \\
\hline Post-operative infection, n (\%) & $19(12)$ & $3(16)$ & $0.570^{\mathrm{a}}$ & 1.590 \\
\hline Place of acquisition - classification, n (\%) & $154(100)$ & $34(22)$ & 0.790 & - \\
\hline Community-acquired, n (\%) & $83(54)$ & $18(22)$ & - & 1.000 \\
\hline Healthcare-associated, n (\%) & $45(29)$ & $9(20)$ & - & 1.330 \\
\hline Hospital-acquired, n (\%) & $26(17)$ & $7(27)$ & - & 1.474 \\
\hline Extent of infection - classification, n (\%) & $154(100)$ & $34(22)$ & $0.195^{\mathrm{a}}$ & - \\
\hline Uncomplicated, n (\%) & $25(16)$ & $3(12)$ & - & 1.000 \\
\hline Complicated, n (\%) & $129(84)$ & $31(24)$ & - & 2.320 \\
\hline
\end{tabular}

${ }^{a}$ Fisher's exact test; AIDS acquired immune deficiency syndrome, DR drug-resistant, OR odds ratio, ATB I non-pseudomonal cephalosporin or ciprofloxacin plus metronidazole, ATB 2 piperacillin/tazobactam 
age $\geq 70$ with an adjusted OR $\left(\mathrm{CI}_{95 \%}\right)=4.677(1.260$ 17.358), solid tumour with an adjusted $\mathrm{OR}\left(\mathrm{CI}_{95 \%}\right)=$ $3.127(1.183-8.266)$ and sensitivity to non-pseudomonal cephalosporin or ciprofloxacin plus metronidazole with an adjusted OR $\left(\mathrm{CI}_{95 \%}\right)=0.368(0.138-0.980)$.

\section{Discussion}

The main finding of our study was the fact that none of the existing classifications had a good discriminating power to identify IAIs caused by pathogens sensitive to the current antibiotic treatment recommendations. This supports the poor utility of the existing classifications of IAI.

Independent risk factors for IAI caused by those pathogens was male gender, for which we cannot find an explanation or similar results in other published studies; and previous invasive procedures in the last year, which were associated with IAI caused by pathogens not sensitive to the shorter antibiotic scheme recommended for CA-IAI, which has also been enlightened by other studies that linked previous invasive procedures with greater rates of colonization and infection with MDR pathogens [18].

Caution should be taken when using antibiotic schemes containing fluroquinolones due to its high potential to induce resistance and its very high resistance rates.

An alternative antibiotic scheme for CA-IAI is piperacillin/tazobactam, which is an antibiotic with a broader spectrum. Postoperative infections were associated with a higher sensitivity to this antibiotic therapy. This result cannot be explained by this study or the literature reviewed. Liver disease also showed an association with increased sensitivity to this antibiotic therapy. Sargenti et al. [34] revealed that patients with liver disease have mainly HCA-IAIs and HA-IAIS, which are often caused by bacteria resistant to commonly used antibiotics, piperacillin/tazobactam might be an option for this group of patients [35].

Our data revealed that age $\geq 70$ years was associated to an increased hospital mortality, which is also supported by the conclusions of other studies [15]. Higher age was also connected, by many studies, to a greater prevalence of DR pathogens, which has been implicated in an augmented mortality rate [36-38]. Solid tumour was the comorbidity that presented a connection with greater mortality, which can be clarified by the higher prevalence of DR pathogens that will result in an increased mortality rate [12, 36-38]. Patients with pathogens sensitive to non-pseudomonal cephalosporin or ciprofloxacin plus metronidazole had an associated lower hospital mortality, in this study. This antibiotic scheme recommended for community-acquired infections is the shortest spectrum one, pathogens sensitive to this regimen are less resistant, having adequate antibiotic therapy more frequently and causing infection with lower severity, which can explain this association.
The total score of CCI was associated with increased hospital mortality in accordance with the study by Montravers et al. [15], that also revealed that the presence of one or more comorbidities had a predictive value for hospital mortality.

In our study, most of the patients had blood cultures taken $(79 \%)$ and more than half were positive (57\%), which is similar to the results of Krobot et al. [21] (43\%), but considerably higher than the data observed by Montravers et al. [15] (6\%). Microbiological cultures, including blood cultures, in IAIs are extremely important to establish an adequate antibiotic therapy and should be collected in every patient with IAI $[3,9,12]$.

The distribution of isolated pathogens, in our study, was identical to other reports, being Escherichia coli the most frequent, independently of the classification used $[5,15,21,39-41]$. The prevalence of monomicrobial IAIs (62\%) was much superior in comparison to the studies by Claridge et al. [41] (41\%) and Shah et al. [42] (33\%).

In our study the rate of inadequate antibiotic therapy (36\%) was within the range described in similar studies: between 13 and 44\% [21]. and it was not associated with increased hospital mortality which was also observed by Montravers et al. [15], but opposed to other several studies $[5,13,30]$. Timing and adequacy of source control are recognized as major prognostic factors and those were not targeted in our study and might explain this finding.

The hospital mortality observed in this study is higher than the described by Sartelli et al. [40] (22\% vs. 11\%), but comparable to the results presented by Montravers et al. [15]: $22 \%$ vs. $24 \%$ in CA-IAIs; $20 \%$ in HCA-IAIs and $27 \%$ vs. $23 \%$ in nosocomial IAIs.

Our study has some limitations. Firstly, since it is a single-centred study, the analysis was based on local data and resistance patterns. Being a retrospective study, data collection was limited to the existing records. Although all variables thought to be relevant were collected in the present study, there is always the possibility of additional variables not considered here to be linked to the outcome studied. Therefore, the results of this study must be interpreted prudently.

We have not found studies that investigated the discrimination of different classifications of IAI on the selection of the best antibiotic therapy, so we assume that our results could be of value to the clinicians in the field.

\section{Conclusions}

In our study, none of the classifications revealed good accuracy in determining infection by a pathogen sensitive to current treatment guidelines, although gender, comorbidities (namely chronic liver disease, previous 
invasive procedures and post-operative infections) were significantly associated with sensitivity to those antibiotic schemes.

A new classification of IAI that includes patient's risk factors might have a greater potential in distinguish IAIs by sensitive pathogens allowing a better choice of empiric antibiotic therapy, tailored to individual patient needs with the minimum selective pressure.

\section{Supplementary information}

Supplementary information accompanies this paper at https://doi.org/10. 1186/s12879-019-4604-0.

Additional file 1. ICD-9 selected codes. Selected codes of the international statistical classification of diseases and related health problems 9th revision (ICD-9) to achieve the first selection of patients.

Additional file 2. Case report form. The case report form created and used to collect the data from the final selection of patients.

\section{Abbreviations}

AIDS: Acquired immune deficiency syndrome; ATB 1: Non-pseudomonal cephalosporin or ciprofloxacin plus metronidazole; ATB 2: Piperacillin/ tazobactam; ATB: Antibiotic; AUROC: Area under receiver operating characteristics; CA-IAI: Community-acquired intra-abdominal infection; CCl: Charlson Comorbidity Index; CHUP: Centro Hospitalar Universitário do Porto; $\mathrm{Cl}_{95 \%}$ : 95\% Confidence interval; ClAl: Complicated intra-abdominal Infection; DR: Drug-resistant; HA-IAI: Hospital-acquired intra-abdominal infection; HCA-IAI: Healthcare-associated intra-abdominal infection; IAI: Intraabdominal infection; ICD-9: International Statistical Classification of Diseases and Related Health Problems 9th revision; IQR: Inter-quartile range; KPS: Karnofsky Performance Status Scale; MDR: Multidrug-resistant; OR: Odds ratio; ROC: Receiver operating characteristics; SD: Standard deviation; SPSS: Statistical Package for the Social Sciences; uIAI: Uncomplicated intraabdominal infection

\section{Acknowledgements}

None.

\section{Authors' contributions}

JSN and TC were responsible for study concept and design. JSN acquired the data. JSN and TC were responsible for analysis and interpretation of data. JSN was responsible for drafting the manuscript. All authors participated in the analysis and interpretation of the data, clinical revision of the manuscript and final approval of the version to be published.

\section{Funding}

No funding was obtained for this study.

\section{Availability of data and materials}

The datasets generated and analysed during the current study are not publicly available since they are currently in use for other studies, but are available from the corresponding author on reasonable request.

\section{Ethics approval and consent to participate}

The study was approved by the local ethics committee, Departamento de Ensino, Formação e Investigação (DEFI) of Centro Hospitalar Universitário do Porto (CHUP) - ref. 2017.226(195-DEFI/187-CES). The need for consent was waived by the local ethics committee and patient data was de-identified.

\section{Consent for publication}

Not applicable.

\section{Competing interests}

The authors declare that they have no competing interests.

\section{Author details}

'Instituto de Ciências Biomédicas Abel Salazar, Universidade do Porto (ICBAS-UP), Rua de Jorge Viterbo Ferreira n. ${ }^{\circ}$ 228, Porto 4050-313, Portugal. ${ }^{2}$ Intensive Care Unit, Unidade de Cuidados Intensivos Polivalente, Hospital de Santo António - Centro Hospitalar Universitário do Porto (HSA-CHUP), Largo Prof. Abel Salazar, Porto 4099-001, Portugal.

Received: 22 July 2019 Accepted: 29 October 2019

Published online: 21 November 2019

\section{References}

1. Lopez N, Kobayashi L, Coimbra R. A comprehensive review of abdominal infections. World J Emerg Surg. 2011;6:7.

2. Lee $Y R$, et al. Complicated intra-abdominal infections: the old antimicrobials and the new players. Drugs. 2015;75(18):2097-117.

3. Montravers $P$, et al. Guidelines for management of intra-abdominal infections. Anaesth Crit Care Pain Med. 2015;34(2):117-30.

4. Hoffmann C, et al. Treatment Modalities and Antimicrobial Stewardship Initiatives in the Management of Intra-Abdominal Infections. Antibiotics (Basel). 2016:5(1). https://doi.org/10.3390/antibiotics5010011.

5. Huang $L L$, et al. Guideline-concordant versus discordant antimicrobial therapy in patients with community-onset complicated intra-abdominal infections. Infect Control Hosp Epidemiol. 2016;37(7):855-8.

6. Sartelli $M$, et al. Antimicrobials: a global alliance for optimizing their rational use in intra-abdominal infections (AGORA). World J Emerg Surg. 2016;11:33.

7. Blot S, De Waele JJ, Vogelaers D. Essentials for selecting antimicrobial therapy for intra-abdominal infections. Drugs. 2012;72(6):e17-32.

8. Menichetti F, Sganga G. Definition and classification of intra-abdominal infections. J Chemother. 2009;21(Suppl 1):3-4.

9. Sartelli $M$, et al. 2013 WSES guidelines for management of intra-abdominal infections. World J Emerg Surg. 2013;8(1):3.

10. Sartelli M. A focus on intra-abdominal infections. World J Emerg Surg. 2010;5:9.

11. De Simone B, et al. Benefits of WSES guidelines application for the management of intra-abdominal infections. World J Emerg Surg. 2015;10:18.

12. Sartelli $M$, et al. Antimicrobial management of intra-abdominal infections: literature's quidelines. World J Gastroenterol. 2012;18(9):865-71.

13. Solomkin JS, et al. Diagnosis and management of complicated intraabdominal infection in adults and children: guidelines by the surgical infection society and the Infectious Diseases Society of America. Clin Infect Dis. 2010;50(2):133-64.

14. Solomkin JS, et al. Guidelines for the selection of anti-infective agents for complicated intra-abdominal infections. Clin Infect Dis. 2003;37(8): 997-1005.

15. Montravers $\mathrm{P}$, et al. Clinical and microbiological profiles of communityacquired and nosocomial intra-abdominal infections: results of the French prospective, observational EBIIA study. J Antimicrob Chemother. 2009:63(4):785-94

16. Sartelli $\mathrm{M}$, et al. Complicated intra-abdominal infections in Europe: a comprehensive review of the CIAO study. World J Emerg Surg. 2012;7(1):36.

17. Garner, J.S., et al., [CDC definitions for nosocomial infections 1988]. Z Arztl Fortbild (Jena), 1991 85(17): p. 818-27.

18. Cardoso T, et al. Classification of healthcare-associated infection: a systematic review 10 years after the first proposal. BMC Med. 2014;12:40.

19. Friedman ND, et al. Health care--associated bloodstream infections in adults: a reason to change the accepted definition of community-acquired infections. Ann Intern Med. 2002;137(10):791-7.

20. Guilbart $\mathrm{M}$, et al. Compliance with an empirical antimicrobial protocol improves the outcome of complicated intra-abdominal infections: a prospective observational study. Br J Anaesth. 2016;117(1):66-72.

21. Krobot $K$, et al. Effect of inappropriate initial empiric antibiotic therapy on outcome of patients with community-acquired intra-abdominal infections requiring surgery. Eur J Clin Microbiol Infect Dis. 2004;23(9):682-7.

22. Davey PG, Marwick C. Appropriate vs. inappropriate antimicrobial therapy. Clin Microbiol Infect. 2008;14(Suppl 3):15-21.

23. Mazuski JE, et al. The surgical infection society guidelines on antimicrobial therapy for intra-abdominal infections: an executive summary. Surg Infect. 2002;3(3):161-73.

24. Sartelli $\mathrm{M}$, et al. WSES consensus conference: quidelines for first-line management of intra-abdominal infections. World J Emerg Surg. 2011;6:2. 
25. Yellin AE, et al. The role of Pseudomonas species in patients treated with ampicillin and Sulbactam for gangrenous and perforated appendicitis. Surg Gynecol Obstet. 1985;161(4):303-7.

26. Mosdell DM, et al. Antibiotic treatment for surgical peritonitis. Ann Surg. 1991;214(5):543-9.

27. Berne TV, et al. Antibiotic management of surgically treated gangrenous or perforated appendicitis. Comparison of gentamicin and clindamycin versus cefamandole versus cefoperazone. Am J Surg. 1982;144(1):8-13.

28. Falagas $M E$, et al. Risk factors leading to clinical failure in the treatment of intra-abdominal or skin/soft tissue infections. Eur J Clin Microbiol Infect Dis. 1996;15(12):913-21.

29. Sturkenboom MC, et al. Inappropriate initial treatment of secondary intraabdominal infections leads to increased risk of clinical failure and costs. $\mathrm{Br}$ J Clin Pharmacol. 2005;60(4):438-43.

30. Montravers $P$, et al. Emergence of antibiotic-resistant bacteria in cases of peritonitis after intraabdominal surgery affects the efficacy of empirical antimicrobial therapy. Clin Infect Dis. 1996;23(3):486-94.

31. Feiring $E$, Walter $A B$. Antimicrobial stewardship: a qualitative study of the development of national guidelines for antibiotic use in hospitals. BMC Health Serv Res. 2017;17(1):747.

32. Karnofsky, D.A. and J.H. Burchenal, The Clinical Evaluation of Chemotherapeutic Agents in Cancer. C. M. MacLeod, Ed., 1949(Evaluation of Chemotherapeutic Agents, Columbia University Press): p. 196.

33. Charlson ME, et al. A new method of classifying prognostic comorbidity in longitudinal studies: development and validation. J Chronic Dis. 1987;40(5): 373-83.

34. Sargenti K, et al. Healthcare-associated and nosocomial bacterial infections in cirrhosis: predictors and impact on outcome. Liver Int. 2015;35(2):391-400

35. Merli $M$, et al. An empirical broad spectrum antibiotic therapy in healthcare-associated infections improves survival in patients with cirrhosis: a randomized trial. Hepatology. 2016;63(5):1632-9.

36. Christou NV, et al. Management of intra-abdominal infections. The case for intraoperative cultures and comprehensive broad-spectrum antibiotic coverage. The Canadian intra-abdominal infection study group. Arch Surg. 1996;131(11):1193-201

37. Barie PS, et al. A randomized, double-blind clinical trial comparing cefepime plus metronidazole with imipenem-cilastatin in the treatment of complicated intra-abdominal infections. Cefepime intra-abdominal infection study group. Arch Surg. 1997;132(12):1294-302.

38. Hopkins JA, Lee JC, Wilson SE. Susceptibility of intra-abdominal isolates at operation: a predictor of postoperative infection. Am Surg. 1993; 59(12):791-6.

39. Zhang S, Huang W. Epidemiological study of community- and hospitalacquired intraabdominal infections. Chin J Traumatol. 2015;18(2):84-9.

40. Sartelli $M$, et al. Complicated intra-abdominal infections worldwide: the definitive data of the CIAOW study. World J Emerg Surg. 2014;9:37.

41. Claridge JA, et al. Bacterial species-specific hospital mortality rate for intraabdominal infections. Surg Infect. 2014;15(3):194-9.

42. Shah PM, et al. Do Polymicrobial intra-abdominal infections have worse outcomes than Monomicrobial intra-abdominal infections? Surg Infect. 2016;17(1):27-31.

\section{Publisher's Note}

Springer Nature remains neutral with regard to jurisdictional claims in published maps and institutional affiliations.

Ready to submit your research? Choose BMC and benefit from:

- fast, convenient online submission

- thorough peer review by experienced researchers in your field

- rapid publication on acceptance

- support for research data, including large and complex data types

- gold Open Access which fosters wider collaboration and increased citations

- maximum visibility for your research: over $100 \mathrm{M}$ website views per year

At $\mathrm{BMC}$, research is always in progress.

Learn more biomedcentral.com/submissions 